\title{
Squamous Odontogenic Tumor of Maxilla - A Rare Case Report
}

\author{
Dr. Gayatri Rath $\mathrm{MD}^{1}$, Dr. Asaranti Kar, $\mathrm{MD}^{2}$, Dr. Goutami Das Nayak ${ }^{3}$, Dr. Chandraprava Mishra ${ }^{4}$ \\ ${ }^{1}$ Assistant Professor, Department of Pathology, S.C.B.Medical College, Cuttack, India \\ ${ }^{2}$ Associate Professor, Department of Pathology, S.C.B. Medical College, CTC, Odisha-753007, India \\ ${ }^{3,}$ PG, Pathology, S .C. B. Medical College, Cuttack
}

\begin{abstract}
Squamous odontogenic tumors (SOTs) are rare benign odontogenic epithelial neoplasms with very low recurrence rate and absolutely no malignant potentiality. The average age at presentation is 38.2 year, though a wider age group of affection from 1st to 8th decade is noted. The common presentation is a slow growing, painless expansile swelling in the maxilla or mandible. Owing to its unique radiological and distinct histopathological features of nests of bland looking squamous epithelial cells in a fibrocollagenous stroma, it was put into a separate entity in 1975. Extensive search of the literature yielded only about 50 cases reported till date. Patients have an excellent outcome as complete cure is achieved after total enucleation and thorough curettage. The significance of detecting such a lesion lies in the fact that it must be clinically, radiologically and histomorphologically distinguished from lesions like acanthomaous ameloblastoma and intraosseous squamous cell carcinoma which have worse prognosis than SOTs.. We report a case of SOT in a 45 year old male in maxilla which was clinically diagnosed as ameloblastoma.
\end{abstract}

Keywords: maxilla, squamous odontogenic tumor, ameloblastoma

\section{Introduction}

Squamous odontogenic tumors (SOTs) are rare benign jaw tumors, being locally infiltrative in nature. They almost never turn to malignancy. It was recognized as a separate entity in the year 1975 and till date only about 50 cases have been reported ${ }^{[1]}$. The molar region of mandible and incisor teeth region of maxilla are the most common sites of affection. Even though it can present with wide age range, the peak age of presentation is at 38.2 years with slight male preponderance. It usually is solitary though multifocal involvement can be seen and affects mandible more frequently.

The tumor has a unique radiological picture of unilocular radiolucency and distinctive microscopic picture of islands of bland looking squamous epithelial cells in a background of dense collagenous stroma. Occasional cystic degeneration and/or calcification may be noticed in the epithelial islands ${ }^{[2]}$. These patients have a very good prognosis with complete cure on total excision and curettage of the mass. We report a case of squamous odontogenic tumor, with a long history of 7 years duration which shows the benign nature of the lesion. We report this case because of its rarity and for inclusion of such a case in differential diagnosis of cystic jaw lesions.

\section{Case Report}

A 45 year old male, presented to the dental OPD with complains of gradual, painless swelling in the left side of face, over left maxillary region for last 7 years. On general examination, patient was of average body built. There was mild pallor, no icterus, cyanosis or lymphadenopathy. Systemic examination did not reveal any abnormalities.

On local examination, there was a firm swelling measuring about 3x2x1 cm over the left maxilla. (Fig.1a) Skin over the swelling was free and healthy with no surface ulceration or hyperemia or any other change. From inner side the oral cavity showed a mass lesion in the posterior part which was non-tender and globular and measured approximately $3 \mathrm{~cm}$ in diameter.(Fig.1b)Radiological examination of left jaw showed a unilocular radiolucent area with alveolar bone loss, localized between the roots of the upper left lateral incisors.

CT scan revealed a well circumscribed irregular homogeneous hypodense lesion in maxilla measuring approximately $3 \mathrm{~cm}$ in diameter (Fig.2).Basing on the clinical and radiological findings, a provisional diagnosis of benign space occupying lesion of upper jaw possibly ameloblastoma was made. Routine hematological parameters were within normal limits. Fine needle aspiration showed few mature squamous epithelial cells and scattered spindle cells. Incisional biopsy was taken from the lesion and sent for histopathological study. Grossly, formalin preserved grayish white tissue measuring $1 \times 0.8 \mathrm{~cm}$ was received. Tissue section showed, small fragments of trabecular bone, distinct islands of tumor tissue comprising of bland looking squamous epithelial cells in a background of cellular, collagenized fibrous tissue stroma(Fig.3a). Some of the tumor islands showed presence of keratin in the center (Fig.3b).Features of malignancy like cellular atypia, high mitotic count, infiltrative margin and/or necrosis were absent. There was no palisading around cell nests excluding a diagnosis of ameloblastoma. Hence, a diagnosis of squamous odontogenic tumor was made.

\section{Discussion}

Benign odontogenic tumors include the well-known entities like ameloblastomas, squamous odontogenic tumours, calcifying epithelial odontogenic tumor and adenomatoid odontogenic tumor. SOT is a very rare entity, found in any area of the alveolar bone. 


\section{International Journal of Science and Research (IJSR) \\ ISSN (Online): 2319-7064 \\ Index Copernicus Value (2013): 6.14 | Impact Factor (2014): 5.611}

Leider et al have reported a rare familial tendency of this neoplasm with affection of 3 siblings of a single family. ${ }^{[3]}$ Present case showed no familial occurrence. The pathogenesis of SOT is not yet clearly known. It is supposed to originate from the rests of Malassez, gingival surface epithelium or from remnants of the dental lamina. But recently, most researchers have pointed toward a periodontal ligament origin for the central variant of the lesion. ${ }^{[4]}$ The tumor takes a completely benign course with no malignant potential or even local recurrences. It often remains undiagnosed and many times detected as an incidental finding as patient remains asymptomatic in most cases. Although any age group from $1^{\text {st }}$ to $8^{\text {th }}$ decade is susceptible, but the average age of affection is 38 years with a mild male preponderance. The most common sites of affection are molar region in the mandible and incisor teeth area of the maxilla ${ }^{[5]}$. SOTs, occurring in the maxilla were found to be more aggressive than in the mandible probably due to the anatomy, porous and medullary nature of the bone ${ }^{[6]}$. Clinically, SOTs present as a slow growing lesion leading to gradual increase in the volume of the maxilla or mandible, tooth mobility and displacement, sometimes ulceration. Radiologically, a broad list of possible diagnoses include developmental or noninflammatory odontogenic cysts, inflammatory odontogenic cysts, odontogenic tumors, hematological disorders, such as Langerhan's cell histiocytosis and multiple myeloma and bone pathology, such as central giant cell lesion and metastasis ${ }^{[7]}$. The classical radiological finding shows a unilocular and triangular shaped radiolucency of the alveolar bone, with wide base: the radiolucency localized between the diverging apices of the adjacent roots ${ }^{[8]}$.Grossly the tumor size varies and depends on the duration of the tumor.

Microscopy shows cytologically bland looking squamous epithelium in a moderately cellular fibrocollagenous stroma. Classically, the epithelium is arranged in rounded or irregular islands that can vary significantly in shape and size. These squamous islands are smoothly contoured and well demarcated from the surrounding stroma. There may be central cystic degeneration and scattered calcification. But, the ameloblastic differentiation in form of peripheral columnar cells with nuclear palisading is absent in SOTs making it a special category, distinct from other jaw tumors. In our case multiple islands of squamous epithelium with surrounding connective tissue were seen but without any peripheral palisading thus differentiating it from follicular ameloblastoma. Lack of features of malignancy excluded the possibility of squamous cell carcinoma which is also a close differential diagnosis of such lesions. IHC studies conducted by Tatemoto et al and Ya mada et al on Squamous Odontogenic Tumour confirmed the proliferative activity of odontogenic epithelium by showing intense staining for keratin 13/16 and squamous cells showed a strong positive reaction for involucrin staining ${ }^{[9]}$.Being completely benign in nature, squamous odontogenic tumors have a very good prognosis with complete cure on total enucleation and curettage of the tumor tissue. After receiving the diagnosis the patient underwent total excision of thelesion .The histopathological examination of the excised tumor also revealed features of SOT without any evidence of malignancy. The patient is doing well till date.

\section{Institution where work was done}

S. C. B. Medical College, Cuttack, Odisha-753007, India

\section{Conflict of interest}

Nil

\section{Acknowledgement}

Nil

\section{If presented in any conference/ meeting}

No

\section{References}

[1] Rajendran R. Cyst and Tumors of Odontogenic Origin. In: Rajendran R, Sivapathasundharam B, editors. Shafer's Text Book of Oral Pathology. 5th ed. Noida: Elservier; 2005. pp. 398-400.

[2] Schwartz-Arad D, Lustmann J, Ulmansky M. Squamous odontogenic tumour. Review of literature and case report. Int J Oral Maxillofac Surg. 1990;19:327-30.

[3] Leider AS, Jonker LA, Cook HE. Multicentric familial squamous odontogenic tumour. Oral Surg Oral MedOral Pathol. 1989;68:175-81.

[4] Badni M,Nagaraja A, Kamath VV. Squamous odontogenic tumor: A case report and review of literature. J Oral Maxillofac Pathol. 2012 Jan-Apr; 16: 113-17.

[5] Kim K, Mintz SM, Stevens J. Squamous odontogenic tumour causing erosion of the lingual cortical plate in the mandible: A report of 2 cases. J Oral Maxillofac Surg. 2007;65:1227-31.

[6] Barrios TJ, Sudol JC, Cleveland DB. Squamous odontogenic tumor associated with an erupting maxillary canine: Case report. $J$ Oral Maxillofac Surg. 2004;62:742-4.

[7] Mardones NR, Gamba TO, Flores IL, Almeida SM, Lopes SLPC. Squamous Odontogenic Tumor: Literature Review Focusing on the Radiographic Features and Differential Diagnosis.Open Dent J. 2015; 9: 154-8.

[8] Haghighat K, Kalmar JR, Mariotti AJ, Squamous Odontogenic Tumour, Diagnosis and Management. J Periodontol 2002; 73: 653-56.

[9] Tatemoto Y, Okada Y, Mori M. Squamous odontogenic tumor: Immunohistochemical identification of keratins. Oral Surg Oral Med Oral Pathol. 1989;67:63-7. 


\section{Legends}
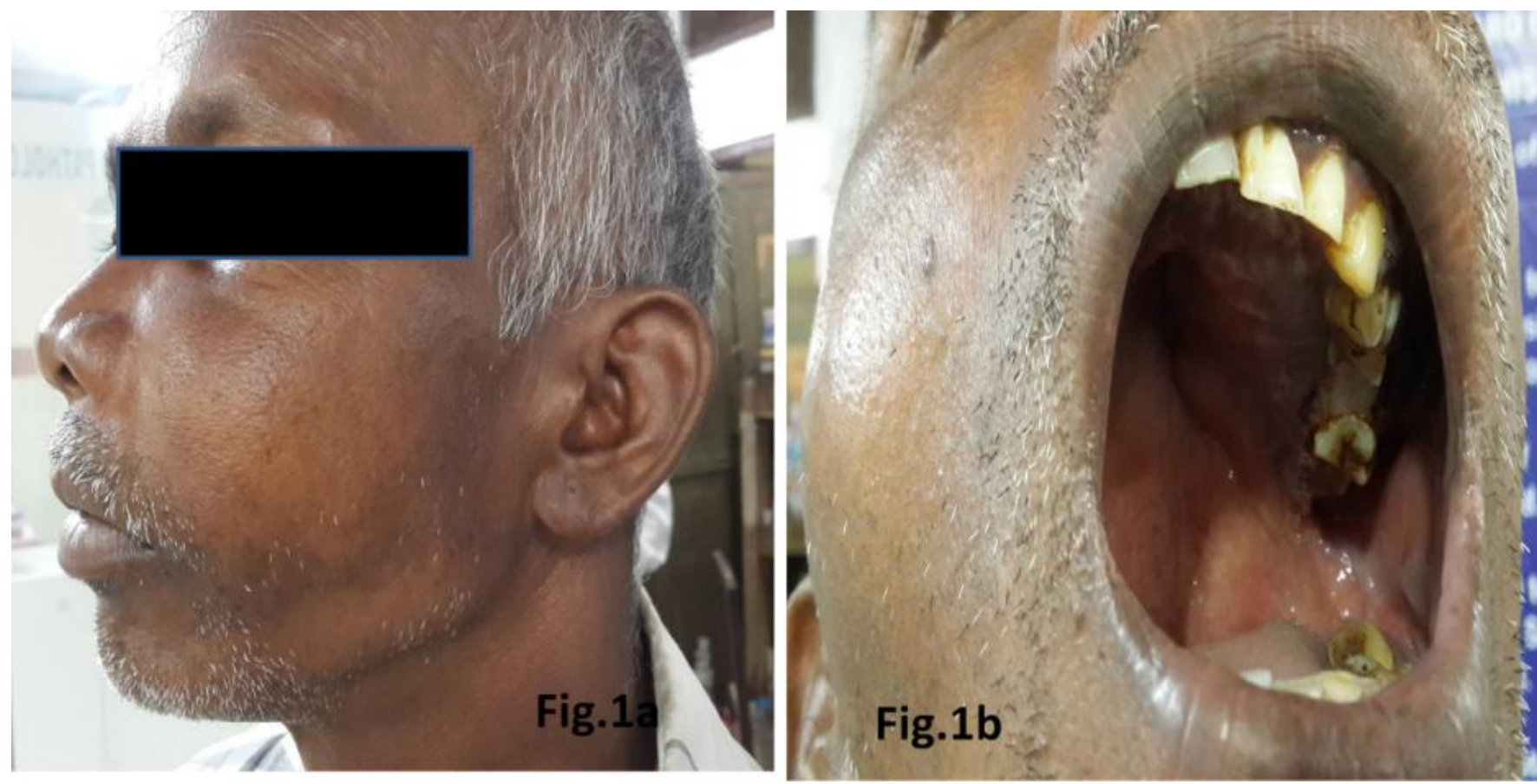

Figure 1: a-Patient's photograph showing form nontender mass on left maxilla. b- Globular swelling inside oral cavity

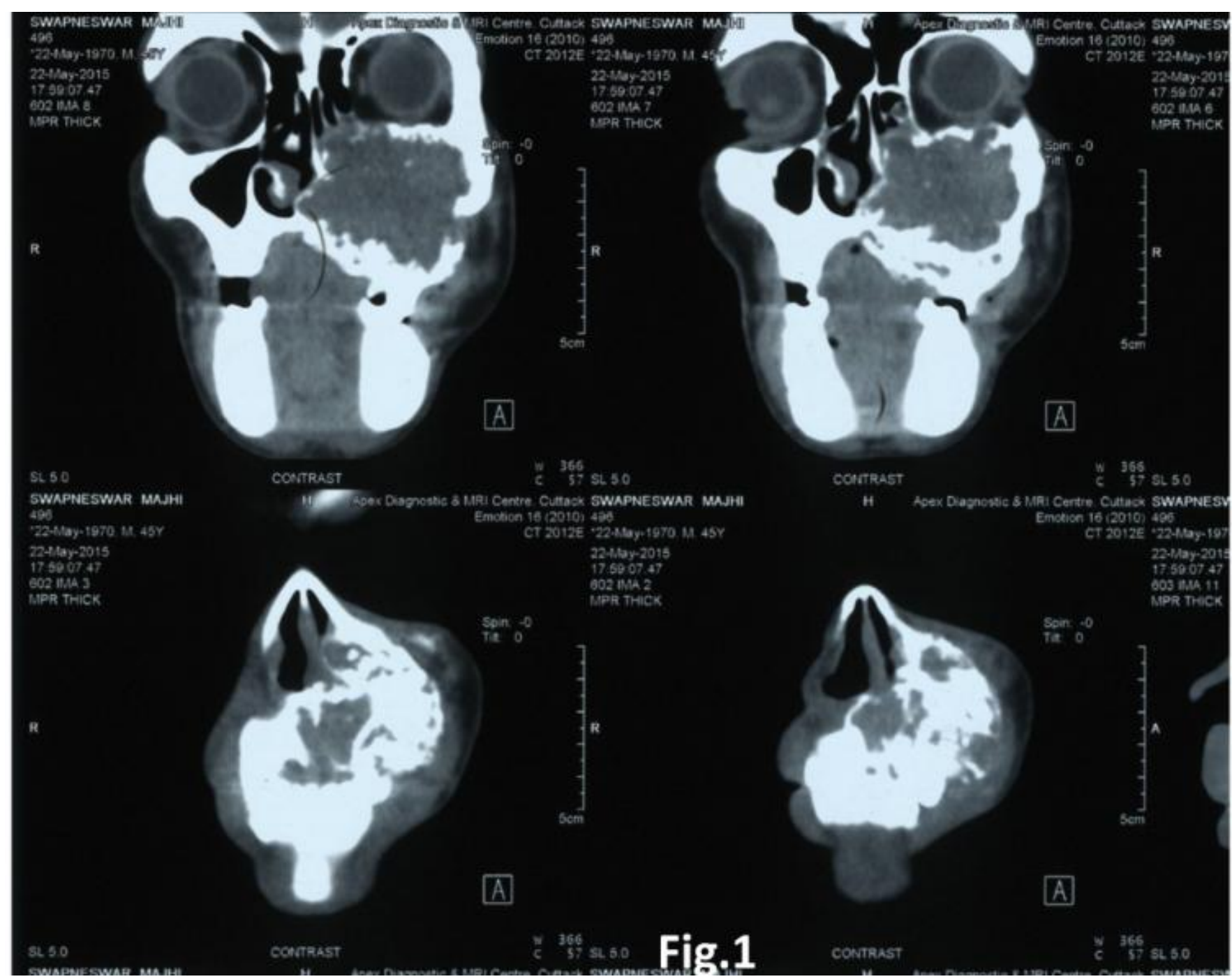

Figure 2: CT scan showing a homogeneous hypodense space occupying lesion in left maxilla.

\section{Volume 5 Issue 3, March 2016} www.ijsr.net 


\section{International Journal of Science and Research (IJSR) \\ ISSN (Online): 2319-7064}

Index Copernicus Value (2013): 6.14 | Impact Factor (2014): 5.611

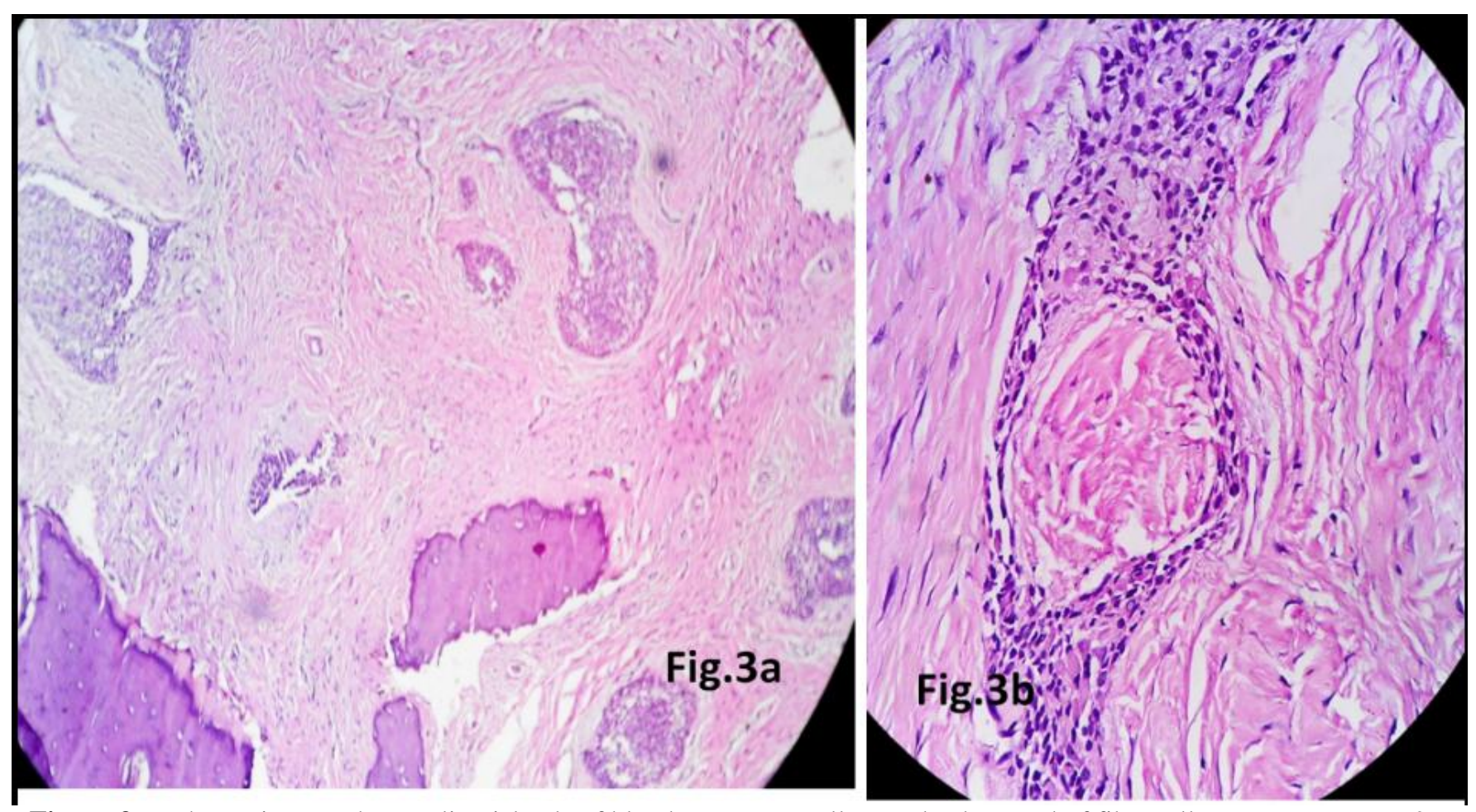

Figure 3: a-Photomicrograph revealing islands of bland squamous cells over background of fibrocollagenous stroma. H\&E stain x 100.b-Presence of keratin in center of squamous island. H\&E stainx 400.

\section{Author Profile}

Dr. Asaranti Kar, MD is Associate Professor, Department of Pathology, S.C.B. Medical College, CTC, Odisha-753007. JT. Secy. IAPM HQ,

Secretary, Odisha Chapter, IAC

Editor, HQ CME Proceedings

Peer Reviewer, IJPM, IJO, Acta cytologica

Member \& Resource person, Medical Education Committee, MCI

Member, Editorial Board, IJPM 